\title{
Reducing the FCI Gender Gap
}

\author{
Vincent P. Coletta
}

Department of Physics, Loyola Marymount University, Los Angeles, CA 90045 USA

\begin{abstract}
After introducing several new elements into an introductory mechanics course for life science students, we observed a substantial reduction in the gender gap on the Force Concept Inventory (FCI). Among those students with the strongest scientific reasoning abilities, where previously the gender gap had been largest, the gender gap was completely eliminated. The course used the Thinking in Physics curriculum, an interactive engagement pedagogy aimed at developing general thinking and problem solving skills along with an understanding of physics. The new elements, designed to reduce stereotype threat and to improve the experience of female students, included giving students a selfaffirmation writing exercise created by researchers at the University of Colorado, providing a learning guide, and assessing and interviewing students at the beginning of the course.
\end{abstract}

Keywords: Scientific reasoning, introductory mechanics, gender, stereotype threat PACS: $01.40 . \mathrm{Fk}$

\section{INTRODUCTION}

A gender gap in performance on the Force Concept Inventory (FCI) and the Force and Motion Concept Evaluation (FMCE) has been widely observed [1,2,3], with males achieving consistently higher average normalized gains than females. Some have speculated that the test itself is gender biased [4]. Osborn Popp, Meltzer, and Megowan-Romanowicz have presented evidence that the test is not systematically biased in favor of males [5], suggesting that the observed gap represents a real difference between males and females in the conceptual understanding achieved in IE introductory mechanics.

In 2010, researchers at the University of Colorado (CU) published a paper in Science [6] in which they argued that stereotype threat [7] is a cause of the gender gap they observed in test results in CU physics classes. They described an intervention they had designed to mitigate stereotype threat. The intervention consists of a brief writing exercise related to students' personal values. Students are asked to choose from a list of a dozen values the two or three values that were most important to them, then to write about why these values were most important, focusing on their feelings. The list of values included relationships with friends and family, creativity, independence, and sense of humor. The exercise was administered at the beginning of the course and again before the first exam. The justification given to students for doing the exercise was that it would give them practice communicating their ideas, and it would be important for them to be able to communicate their ideas about physics in the course. The theory was that this self affirmation would protect students from being preoccupied with negative stereotype thoughts. The CU researchers presented evidence showing that the intervention resulted in the elimination of the gender gap. Among those participating in the intervention, female and male students performed equally well on the FMCE [6, 8]. Steve Pollock and Tiffany Ito generously provided the materials they had used in the CU intervention to allow replication of their method in the study reported in this paper.

\section{THINKING IN PHYSICS}

Our prior research revealed that many students come to physics classes unable to use certain scientific reasoning skills needed to learn physics, and for those students, achieving good conceptual understanding in mechanics is unlikely even in a course using interactive engagement (IE) methods. We found a strong correlation between individual students' normalized gains on the FCI and their preinstruction scores on the Lawson Classroom Test of Scientific Reasoning Ability [9, 10, 11], a result that has been widely replicated $[12,13,14,15,16]$. Together with Jeffrey Phillips, we created the Thinking in Physics (TIP) curriculum at Loyola Marymount University (LMU) to enhance those reasoning skills in introductory physics courses. Each of us has developed our own courses with somewhat different features, emphasizing different aspects of the TIP 
pedagogy and utilizing it in somewhat different ways. My own version of TIP has focused most recently on finding ways to reduce the FCI gender gap in TIP, as reported in this paper.

Both versions of TIP have the same general features. Both develop general thinking and problem solving skills, and use the context of physics to teach thinking about variables and their relationships. TIP activities include student group work and lab experiments. We require students to keep thinking journals, encouraging metacognitive reflection. TIP utilizes a variety of games and puzzles. In earlier papers we have provided a more detailed description of the TIP curriculum and the improvement in conceptual understanding and problem solving skills achieved in TIP courses [17, 18].

In my introductory mechanics courses for life science students, taught from 2000 to 2006 using IE methods before the TIP curriculum was developed, individual normalized FCI gains $G$ averaged $0.52 \pm$ 0.04 for males and $0.29 \pm 0.02$ for females. (Uncertainties are standard errors). In my courses from 2007 to 2010 I used the TIP curriculum, and individual FCI gains improved for males and especially for females: average $G$ of $0.57 \pm 0.04$ for males and $0.41 \pm 0.03$ for females. Though TIP reduced the difference, a large gender gap remained.

\section{METHODS USED TO REDUCE THE GENDER GAP}

I began using the Colorado self affirmation writing exercises in my TIP classes in 2011. FCI scores increased somewhat for both men and women, but with a bigger increase for women, thus reducing somewhat the gender gap. FCI $G$ averaged 0.60 for men and 0.46 for women, reducing the gap to 0.14 . Based on this improvement, I decided to make additional changes to the TIP curriculum to see if further improvement could be achieved. I knew that test anxiety was a major problem for many of my students, male and female, but that anxiety was more common among female students [19]. Student course evaluations also revealed that many of my students did not fully understand the purpose of some methods used in the course. The evaluations also revealed that most of my students had no real interest in physics. They were taking the course because it was required. Fewer females than males had an interest in physics, and interest can impact learning [20]. The hope was that addressing these issues would help students, especially females. In order to reduce anxiety, increase understanding of course methods, and increase interest in physics, in 2012 I introduced the following changes: 1) a group project; 2) online reading tests; 3 ) a learning guide; 4) interviews.

1) The group project teamed four students who sat at the same table in the LMU interactive physics classroom. They were required to produce a 5 minute YouTube video and a short paper on some application of physics that was of interest to members of the group. I emphasized that the purpose of this project was to focus on something they were already interested in, to study the physics of that thing, and, hopefully, to thereby increase their interest in physics. The topics chosen included basketball, soccer, hockey, martial arts, and swimming. Less than one hour of class time was needed to show all of the videos.

2) Online reading tests consisted of five multiple choice questions based on an assigned reading from the text, and were taken by students anytime before the lecture on the material covered in the reading. Using the Blackboard system, students were given three chances to answer the questions. Typically, nearly all students scored a perfect 5 by their third try. Students told me that when their first try resulted in a score of less than 5 , which was usually the case, they went back and read the material again. The objective of the reading tests was to encourage careful reading of the text and to provide a low stress way for students to test their understanding of the material. TIP already used frequent quizzes, for which students typically experience less anxiety than in a full exam.

3) I prepared a five page "Guide to Learning Physics," in which I explained in great detail course objectives, methods, the rationale for those methods, and evidence for their effectiveness. I also offered detailed advice about how to study, utilizing the various elements provided in the course. I provided anonymous quotes from former, offering advice to new students, e.g. "Reading the text carefully, multiple times is very important. Also, when doing problems, don't just go through the motions, but think about why you do each step", "Understanding concepts is actually more important than doing problems because it shows the whole picture and will eventually help with problem solving." The learning guide was discussed during the first class, and students were asked to read and comment on it in their first Thinking Journal entry. From the beginning students had a better understanding of the rationale for course methods and were better prepared for the challenges the course would present.

4) I interviewed each of my students for 15 minutes during the first week of class. The interviews followed testing with the FCI, Lawson's test, an attitude survey, and their submission of their first thinking journal entry, in which they were asked to respond to the following prompts: 1) Tell me something about yourself. 2) Have you had a good 
high school physics course? 3) Your goals for yourself in this course. 4) How much time each week do you plan to study outside of class? 5) Your experience with a concept or belief that you once thought was correct and no longer do, \& how that came to change. 6) Your thoughts on the course objectives and learning guide. I explained that the purpose of the interview was to get to know each of them and to make them more comfortable coming to see me for help with physics when they might need it. When I met with the students, I already knew a lot about them, their activities, their professional aspirations, their strengths and weaknesses, likes and dislikes - some loved their high school physics course, others hated it. Many were concerned that they might not do well in my course either because they did not take high school physics, did not have a good course, or did not do well in it. I was able to assure them that, based on the assessment I did of the class's initial knowledge of physics concepts (the FCI given on the first day of class), almost nobody in the class had a strong knowledge of these concepts and therefore they were not at a disadvantage. The class average FCI preinstruction score was $28 \%$ and only two of the 47 students scored over 50\%.

Establishing a personal relationship with my students during the first week allowed me to understand who they were and for them to feel more comfortable about the course and about talking to me.

\section{RESULTS}

In the fall 2012 class, with 31 females and 16 males, FCI normalized gains were the highest yet achieved by students in any of my classes, averaging 0.60. Gains for both males and females showed significant improvement over prior years. The average gain for males was $0.67 \pm 0.03$ and the average gain for females was $0.56 \pm 0.03$. Thus the gender gap was reduced to 0.11 .

Instead of comparing the average normalized FCI gains of all males and females in the class, it is much more informative to compare the gains of those male and female students who have similar preinstruction scores on the Lawson test. Fig. 1 is a graph of average FCI $G$ vs. average Lawson score for quartiles of male Lawson scores and for quartiles of female Lawson scores in the 2012 class. The graph shows that the highest quartiles of male and female students had nearly identical normalized gains: $0.70 \pm 0.05$ for females vs. $0.71 \pm 0.05$ for males. However, the lowest two female Lawson quartiles had average FCI G's significantly lower than any of the male quartiles' average $G$ 's.
Fig. 2 is a graph of the same variables as in Fig. 1 for my TIP classes taught from 2007 - 2010. Comparing Figs. 1 and 2, we see that average FCI gains were higher in 2012 than in '07 - '10 for all male and female groups with the exception of the highest male quartile. The biggest improvements from '07 - '10 were for the highest female Lawson quartile, with average FCI $G$ increasing from $0.51 \pm 0.04$ to $0.70 \pm 0.05$ and for the lowest male Lawson quartile, with average FCI $G$ increasing from $0.36 \pm 0.07$ to $0.62 \pm 0.08$. In 2012 the gender gap was present only for students in the lowest quartile of Lawson scores. This is in marked contrast to '07-'10, in which the gender gap was greatest among students in the highest quartile (Fig. 2 and [21]).

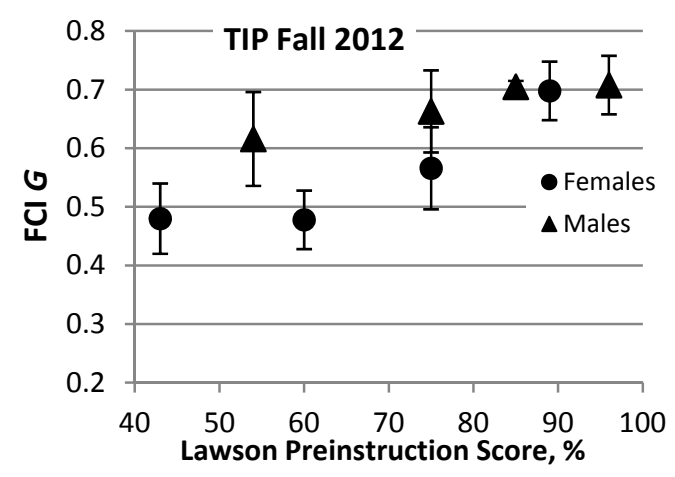

FIGURE 1. Average FCI G vs. average Lawson score for male and female Lawson quartiles in TIP classes, fall, 2012. Error bars indicate standard errors.

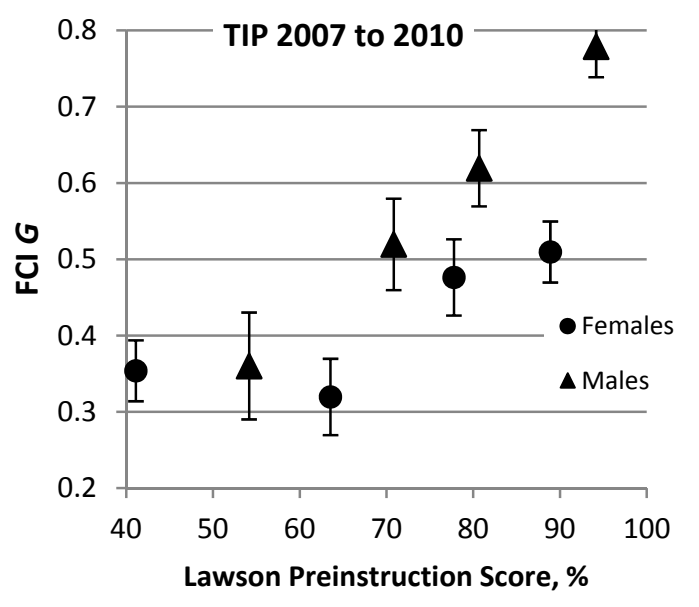

FIGURE 2. Average FCI G vs. average Lawson score for male \& female Lawson quartiles in TIP classes, ' 07 to ' 10 . Error bars indicate standard errors.

Given that the TIP curriculum is designed to improve both scientific reasoning ability and understanding of physics, it is not surprising that the improvement in FCI scores from '07-'10 to '12 was accompanied by improved gains in scientific reasoning. The class average normalized gain on the 
Lawson Test improved from 0.28 to 0.40 for females and improved from 0.33 to 0.43 for males.

Figs. 3 and 4 show, for females and males respectively, pre and post instruction average Lawson scores for each of the pre instruction Lawson quartiles. Those students with the lowest prescores had the largest gains: increasing from $45 \%$ to $70 \%$ for females and from $54 \%$ to $83 \%$ for males.

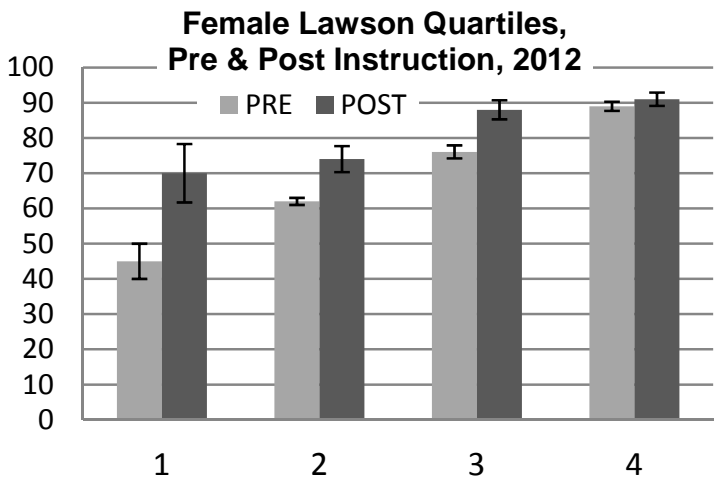

FIGURE 3. Average Lawson scores, pre and post instruction, for female Lawson quartiles in TIP classes, fall, 2012. Error bars indicate standard errors.

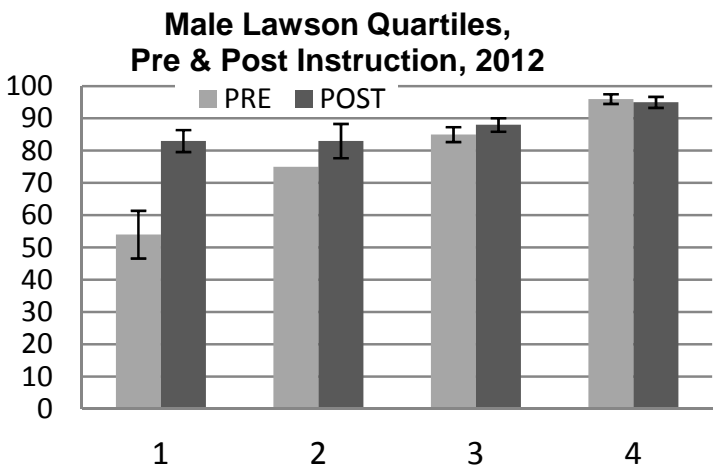

FIGURE 4. Average Lawson scores, pre and post instruction, for male Lawson quartiles in TIP classes, fall, 2012. Error bars indicate standard errors $\left(2^{\text {nd }}\right.$ quartile prescores were all the same).

\section{SUMMARY AND CONCLUSIONS}

The changes to the TIP curriculum introduced in fall 2012 appear to have had their intended effect of improving learning for all students, having an especially strong effect for female students with the highest Lawson preinstruction scores and for male students with the lowest Lawson preinstruction scores. Students' thinking journal entries and informal comments indicated that they appreciated the new course elements, specifically the project, the learning guide, the online tests, and the interviews. Student course evaluations were also very positive, with an average over all questions of 4.5 on a 5 point scale, compared with an average of 4.0 in recent prior years. I was concerned that students might consider the project burdensome, but when I polled them anonymously as to whether I should require projects in my future classes, a surprising $90 \%$ said yes.

The results reported in this paper show that relatively modest changes to the curriculum can have a marked impact on students' feelings about an IE course and on student learning, and can significantly reduce the gender gap, eliminating it altogether for the strongest students. The changes were intended to mitigate stereotype threat, reduce anxiety, increase interest, and improve understanding of course methods. Although it seems reasonable that each of the five changes would contribute to one or more of these goals, it is impossible to say whether all were equally important.

\section{REFERENCES}

1. R.R. Hake, submitted to PERC; online at http://www.physics.indiana.edu/ hake/ Hake.pdf (2002)

2. M. Lorenzo, C. Crouch, and E. Mazur, Am. J. Phys., 74 (2): p. 118-122 (2006).

3. L. E. Kost, S. J. Pollock, and N. D. Finkelstein, Phys. Rev. ST: Phys. Educ. 5: p. 010101 (2009)

4. L. McCullough, J of International Women's Studies 5 (4): p. 20-30.

5. S. E. Osborn Popp, D. E. Meltzer, and C. MegowanRomanowicz, presentation,Am. Ed. Res. Assoc. (2011).

6. A. Miyake et al, Science, 330: p. 1234 -1237 (2010).

7. C. M. Steele and J. Aronson, J. Pers. Soc. Psych. 69: p. 797-811 (1995).

8. L. E. Kost-Smith et al, PERC proceedings 1289: p. 197- 200 (2010).

9. V. P. Coletta and J. A. Phillips, Am. J. Phys., 73: p. 1172-1182 (2005).

10. V. P. Coletta, J. A. Phillips and J. J. Steinert, Phys. Teach., 45: p. 626-629 (2006).

11. V. P. Coletta, J. A. Phillips and J. J. Steinert, Phys. Rev. ST: Phys. Educ. 3: p. 010106-1-010106-5 (2007)

12. M. A. Dubson and S. J. Pollock. AAPT Announcer 36 (2): 90 (2006).

13. K. Diff and N. Tache, AIP Conf Proc. 951: p. 85-87 (2007).

14. P. Pamela and J. Saul, AAPT Announ. 36: p. 89 (2006).

15. P. Nieminem, A. Savinainen, and J. Viiri, Phys. Rev. ST: Phys. Educ. 8: p. 010123-1-010123-10 (2012).

16. 11. B. A. Pyper, AIP Conf Proc. 1413: p. 63- 65 (2011).

17. V. P. Coletta and J. A. Phillips, AIP Conf Proc. 1179: p. 117-120 (2009).

18. V. P. Coletta and J. A. Phillips, AIP Conf Proc. 1289: p. 13- 16 (2010).

19. J. Mallow, J. Sci. Ed. Technol., 3: p. 227-238 (1994).

20. P. Haussler, L. Hoffmann, J. Res. Sci. Teach., 39: p. 870-888 (2002).

21. V. P. Coletta, J. A. Phillips and J. J. Steinert, AIP Conf Proc. 1413: p. 23- 26 (2011). 